\title{
Staff Satisfaction to the Introduction of New Ways of Working in General Hospitals in Nigeria
}

\author{
Article by Maclawrence Kolapo Famuyiwa \\ Apapa General Hospital, Apapa, Lagos, Nigeria \\ Email: maclawrencefamuyiwa@yahoo.com
}

\begin{abstract}
Purpose: The study examines the level of satisfaction that staff of General Hospitals in Nigeria hope to derive from the introduction and implementation of 'New Ways of Working' in General Hospitals in Nigeria.

Methodology: The study was conducted in a typical General Hospital in Nigeria. Satisfaction level to the introduction and implementation of New Ways of Working was assessed by self-administered and pretested questionnaire. Descriptive statistics to explain the demography of the respondents were done; mean score and standard deviation values were used to examine the variables.

Findings: The average mean score of the satisfaction level to the components of new ways of information if introduced was $(3.52 \pm 1.54)$. Respondents showed highest level of satisfaction to the component afford them a free hand to make impactful decisions on their work schedule $(2.20 \pm 1.18)$, and least level of satisfaction when they are provided with means of deriving more information about their work when they are provided with information technology within the hospital premises ( $4.95 \pm 1.85)$.

Research Limitations: More General Hospitals should be involved in new studies for more generalizability.

Practical implications: Staff believe they will derive some satisfaction with the introduction of 'New Ways of Working'.

Social implications: Staff satisfaction to the implementation of 'New Ways of Working' will allow patients to access care with flexibility.

Value of the Paper: The study is promoting the introduction of 'New Ways of Working', to afford staff and patients more flexibility.

Keywords: Satisfaction, Staff, New Ways of Working, General Hospitals.

\section{Introduction}

The craving of out-patient clinics attendees of General Hospitals, nowadays, is for them to rather than their clinic appointments coinciding with their normal working hours, have an arrangement that will allow them ease of access to care at the time most convenient to them, going by the fact that most organizations, they work for, are becoming more complex and eating deeper into their attention and time. 'New Ways of Working' (NWW) has been found welcoming by many organizations the world over (Blok et al., 2012), but this concept is still alien to the public health sector in Nigeria, and it is its adoption that will make patients to satisfy this their craving for flexibility of access to health care.

NWW can be divided into the following components, bricks, bytes and behavior (Baane, Houtkamp, \& Knotter, 2010; Kok, Koops, \& Helms, 2014). According to Kok et al., (2014), bricks are the physical parts and are about all dimensions of the physical work environment, bytes refer to the technological component and concern with the use and application of information technology while behavior entails the personal component and it's about the manager-employee relationship and the way of working of employees and their experiences while doing that work.

Human talent, according to Blok et al. (2012) and Gates (2005) is of greater importance in the implementation of NWW since it is responsible for the sharing of knowledge adaptation
\end{abstract}


and innovation. In the view of Bijl \& Gray (2011), employees are important success factor, since they are essentially meant to handle information overload and need to make themselves easily accessible regardless of time and place.

The advantages of NWW to any organization practicing it, include cost-savings (Baane et al., 2010; Bass, Avolio, \& Atwater, 1996; Bass, Avolio, Jung, \& Berson, 2003), higher staff commitment (Bijl, 2009), better work-life balance (Slijkhuis, 2012) and higher productivity Baane et al., 2010; Doherty, Andrey, \& Johnson, 2000), greater motivation (Baane et al. 2010) and satisfaction (Stam2011), and this explain why many organizations are now adopting NWW, and may explain the strong growth that have followed this adoption by these organizations that have implemented a form of NWW (Blok et al., 2011). Organizations mainly change because they have a certain advantage in mind. However some untoward effects have been noticed in organizations implementing NWW and these include a decrease of social cohesion (Bijl, 2009).

It is the intention of this study to determine the level of satisfaction staff of General Hospitals in Nigeria will derive from the introduction and implementation of NWW, this becomes pertinent so as to establish the willingness of these staff to want to diligently implement NWW to assuage the dissatisfaction their patients are currently having concerning missed momentous clinic appointments which the present way of working is encouraging and which NWW will try to address.

\section{Literature review}

According to Newman et al. (2001), in any health care organization, patient satisfaction is an aftermath of employee satisfaction, so it is imperative of these organizations to view their employees as customers as well and strive to satisfy them by providing a conducive working ambience that augment the service capability of staff through empowered decision making, a measure which they opined will lead to more satisfied employees that would enthusiastically provide a higher level of care resulting in higher patient satisfaction, it is thus important to gauge staff satisfaction for the success of any measure that is aimed to satisfy patients.

\subsection{New ways of working}

'New Ways of Working', on the other hand, has a diverse definition and it is difficult to attribute any universally agreed definition to 'New Ways of Working' (Baane et al, 2010; Baruch, 2001; Volberda, Jansen, Tempelaar, \& Heij, 2011), For example, Bijl (2009) defined NWW as a vision whereby recent developments in information technology act as a catalyst for a better design and management of knowledge work. This involves the reconstruction of the physical work place, the organizational structure and culture, the management style as well as a better design and management of knowledge worker and his manager. This definition has been established to encompass all other definitions as it includes the four most important focus areas (people, organisation, work environment and technology).

Bijl, (2007, 2009) and Blok et al, (2012), all identified four cornerstones of NWW to be:

1. The individual: this includes elements such as motivation and competence (development)

2. The organisation: this includes organisational structure, organisational culture and leadership style.

3. The work environment: this includes office space and design.

4. The technology: this includes ICT equipment and support.

Bijl (2007) also added that a relationship exists between these four cornerstones of NWW described above, and change or renewal is required in all these four cornerstones of NWW in order to achieve the NWW objective.

\subsubsection{The individual and competency (Development)}

Many different skills have been identified to be important for realizing NWW, and according to Stam (2011), the most important of these skills are: managing staff, organising 
one's own work, commitment, networking, independence, decision-making skills, goalorientation, communication, flexible behaviour and collaboration. And it is when these skills are well developed that NWW can be ensured (Pierick, 2009).

\subsubsection{Organization}

Bijl, (2009) and De Leede, and Kraijenbrink, (2014), stated that there are three elements that are closely knitted together within any organisation: vision/ambition, organisational structure and organisational culture. Vision and ambition gives the direction the organisation intends to tow. It is thus mandatory for the vision and the ambition of the organisation to accommodate NWW so as to ensure staff motivation and successful implementation of NWW. This may mean the re-organisation of the hospital structures, tending towards a network structure which allows collaborations between different levels of hospital workers with copious use of ICT for self-management, self-organisation, enterprise and exchange of information (Bijl, 2009, Kuipers, Amelsvoort, \& Krame, 2010).

Organisational culture is about the correlation between how individuals within the organisation want to interact (Bijl, 2009) and how they actually communicate and collaborate with each other (Egmond van, 2010), and leadership plays an important role in this (Egmond van, 2010, Cameron, \& Quinn, (2008) and Keuning, (2007). According to Bijl, (2007, 2009) NWW ensures the need of person-centred leadership, staff support, collaboration, and the realisation of connections with staff.

\subsubsection{Technology}

Introduction of ICT to NWW will help staff to be more productive, more creative and more flexible since this will help the implementation of NWW to be more smooth (Wensing, 2009), will enable collaboration and communication, (Haterd, 2010), and contribute to social cohesion (De Leede, \& Kraijenbrink, 2014).

\subsubsection{Work environment}

A hybrid organisation may be formed with the partial implementation of NWW in which components of a traditional organisation are combined with those following NWW (Stam, 2011). NWW however, aims at working methods free of the constraints of time and place, this involves flexible work spaces within the organisation customized specifically to various sorts of activities (Bijl, 2007, 2009) and Egmond van, (2010). NWW makes the office to become a place where staff gladly physically meet each other there to work together (Bijl, 2009).

Theoretically, Stam (2011) demonstrated that NWW satisfies employees' need, which Baane et al. (2010) suggested will lead to greater motivating effect on staff, but this was not the case in practical studies (Stoffers et al. 2015), this they said may be as a result of few researches into the full impact of NWW within the organisation but rather efforts have been on the nature of NWW and the relationships between its components.

\section{Methodology}

\subsection{Study design, site and participants}

A cross sectional study was conducted in a General Hospitals in Lagos, Nigeria. This hospital serves the major proportion of a section of the Lagos population because it offers enhanced clinical services. This sample size was calculated using Taro Yamane formula as follows:

$\mathrm{n}=. N$.

$1+\mathrm{N}(\mathrm{e})^{2}$

Where:

$\mathrm{n}=$ Sample Size

$\mathrm{N}=$ Elements of population in this study is 357 
South American Journal of Public Health

Volume 4, Issue 2, 2016

$\mathrm{e}=$ Error of sampling, in this study is 10 percent or 0.10 proportion.

Therefore, substitution in the formula:

$$
\begin{aligned}
\mathrm{n} & =\frac{357}{1+357(0.10)^{2}} \\
& =78.12
\end{aligned}
$$

Furthermore, owing to the diverse professional status of the respondents involved in this study, a stratified sampling method was adopted for this study by drawing separate random samples from amongst the different professional cadres found in this General Hospital: Doctors, Dentists, Pharmacists, Physiotherapists, Administrators, Accountants, Medical Records Officers, Nurses and Other Staff. This method was also adopted to draw random samples between the management and non-management staff.

\subsection{Data collection method}

This study used questionnaire for data collection since this is particularly appropriate for deductive research providing an easily accessible and controllable way for collecting and explaining data. The researcher sought for expressions of interest from all surveyed respondents using an introductory letter explaining the aim of the study and the anonymity of the answers, polite reminders were personally given by the respondent three days and repeated again a day to the deadline for the collection of the questionnaire. According to Fox, Crask, \& Kim (1988), pre-notification and follow-ups increase the response rate. The list of concepts also accompanied the questions for clarification purpose.

The study instrument was designed by the researcher after a rigorous literature review (Memish et al, 2014, WHO, 2013, Gautret, 2013, and Al-Tawfiq \& Memish, 2014). After an initial draft of the questionnaire was designed, it was validated in 2 steps. Firstly, the study instrument was discussed with the researcher's supervisor and other senior academics versed in research work to give their expert opinion with respect to its simplicity, relativity and importance. Secondly, a pilot study was conducted by the selection of a small sample of health care professionals $(n=9)$ who gave their opinions on making the questionnaire simpler and shorter. Participants from all professions working within the hospital studied were selected for the pilot study. Amendments from the participants were considered and used in modifying the questionnaire, while ensuring its consistency with the published literature (Memish et al, 2014, WHO, 2013, Gautret, 2013, and Al-Tawfiq \& Memish, 2014). After a thorough discussion, questionnaire was finalized by the researcher and subsequently distributed to the participants for their response. The data of the pilot study was not used for the final analysis. A copy of the questionnaire is included as Appendix 1 in this report.

The questionnaire consists of five sections labelled A-E. The first section of the questionnaire consists of the questions on demographic information: Gender, Age, Education level, Specialty/Department, and job functions. The rest of the sections contain questions on each of the four research questions for this study: The prevailing leadership style, the compatibility of present leadership style to the introduction of 'New Ways of Working', the effect of introduction of 'New Ways of Working' to staff satisfaction and the way of working preferred by the staff. Responses were evaluated through 7 point Likert scale of agreement, A score of 1 was given to strongly agree, 2 to agree, 3 to somewhat agree, 4 to neither agree nor disagree, 5 to somewhat disagree, 6 to disagree and 7 to strongly disagree. A mean score of

5 was considered as agreement to the statement of the research question while score of $\geq 5$ was taken as disagreement to the statement of the research question.

Furthermore, a snapshot approach or cross-sectional study design was employed as the study was conducted at a specific moment in time. As such, there was no time available to conduct a longitudinal study. It was also desirable to know the state of affairs at this specific moment in order to be able to take action in the short term. The primary source of data 
collection for this study was through the use of validated questionnaire and data was collected in May, 2016.

\subsection{Reliability and validity of data collection instrument}

\subsubsection{Reliability}

According to Dooley $(2009$, p. 76$)$ reliability "refers to the degree to which observes scores are free from errors of measurement". Reliability is measured by the consistency of the scores". Cronbach's alpha (Cronbach, 1951), was used to determine the homogeneity of the data collected. The internal reliability of the leadership style questionnaire was determined.

The contents of the questionnaire that was finally used, have reliability coefficient calculated using SPSS v.20 and the value of Cronbach's alpha (Cronbach, 1951) was 0.78, and according to Nunnally (1978), Cronbach's Alpha values higher than 0.7 is considered reliable.

\subsubsection{Validity}

Validated questionnaire was used in this study in order to increase reliability. According to Saunders, Lewis, Thornhill, Booij, \& Verckens, (2011), a validated questionnaire incorporates validity which reflect whether the research is actually measuring what it is supposed to measure, this according to them is the extent to which the collection of data, the techniques used and the analysis ensured for inter-dependent findings.

The content validity of the instrument was carried out by the project supervisor and other senior academics.

\subsection{Data analysis method}

The data generated from this study was analysed using SPSS version 20. The analysis was done in three parts: 1). univariate analysis, 2). bivariate analysis, and 3). multivariate analysis. Mean, median, mode and standard deviation were employed for the univariate analysis, the bivariate analysis for this study was used to establish whether NWW can lead to higher productivity and organisational commitment. Bivariate relationships between 7-item likert scales are analysed using Spearman's correlation coefficient $r$ was used to measure the correlation, because the measurement scale is ranked (Bryman \& Bell, 2011).

Multivariate analysis in this study tested whether distinct variables of leadership lead to a higher staff satisfaction, and also tested whether the introduction of NWW will make the moderator leadership has an effect on staff satisfaction (Dooley, 2009).

\section{Results}

Table 1: Gender of the Respondents

\begin{tabular}{|l|l|l|}
\hline Variable & Number of Respondents & Percentage \\
\hline Gender & & \\
\hline Male & 25 & 30.9 \\
\hline Female & 56 & 69.1 \\
\hline Total & $\mathbf{8 1}$ & $\mathbf{1 0 0}$ \\
\hline
\end{tabular}

Table 1 above shows that $69.1 \%$ of the respondents were female while $30.9 \%$ were male. This indicates that both male and female sexes are represented in the study.

Table 2: Age distribution of the Respondents

\begin{tabular}{|l|l|l|}
\hline Age Range & $\begin{array}{l}\text { Number of } \\
\text { Respondents }\end{array}$ & Percentage \\
\hline 25 \& Below & 1 & 1.2 \\
\hline
\end{tabular}


South American Journal of Public Health

Volume 4, Issue 2, 2016

\begin{tabular}{|l|l|l|}
\hline $26-30$ & 11 & 13.6 \\
\hline $31-35$ & 9 & 11.1 \\
\hline $36-40$ & 16 & 19.8 \\
\hline $41-45$ & 19 & 23.5 \\
\hline $46-50$ & 19 & 23.5 \\
\hline $51-55$ & 5 & 6.2 \\
\hline $56 \&$ Above & 1 & 1.2 \\
\hline Total & $\mathbf{8 1}$ & $\mathbf{1 0 0}$ \\
\hline
\end{tabular}

Table 2 reveals that $80.4 \%$ of the respondents are between 26 and 50 years age range, out of which $60.3 \%$ are within the age group 41 and 50 years. Those below 25 years and those above 56 years of age were $1.2 \%$ respectively of the respondents. The median age is 41.4 years, the mode is 41.4 years, and the mean is 40.6 years.

Table 3: Education Distribution of Respondents

\begin{tabular}{|l|l|l|}
\hline Education Level & $\begin{array}{l}\text { Number of } \\
\text { Respondents }\end{array}$ & Percentage \\
\hline Secondary School & 2 & 2.5 \\
\hline OND/NCE & 8 & 9.9 \\
\hline School of Nursing Certificate & 17 & 21.0 \\
\hline Bachelor/HND & 42 & 51.9 \\
\hline Post Graduate Degree & 11 & 13.6 \\
\hline Others & 1 & 1.2 \\
\hline Total & $\mathbf{8 1}$ & $\mathbf{1 0 0}$ \\
\hline
\end{tabular}

Table 3 indicates that $65.5 \%$ of the respondents have more than a bachelor degree, with $20.8 \%$ of these group of respondents even having a post-graduate degree, $9.9 \%$ had $\mathrm{OND} / \mathrm{NCE}, 21.0 \%$ had a School of Nursing certificate, and only $2.5 \%$ had a Secondary School certificate.

Table 4: Distribution of Respondents by Profession

\begin{tabular}{|l|l|l|}
\hline Specialty/Department & $\begin{array}{l}\text { Number of } \\
\text { Respondents }\end{array}$ & Percentage \\
\hline Nursing & 29 & 35.8 \\
Medical & 11 & 13.6 \\
Dental & 3 & 3.7 \\
Pharmacy & 11 & 13.6 \\
Physiotherapy & 2 & 2.5 \\
Health Information & 5 & 6.2 \\
Management & 6 & 7.4 \\
Laboratory & 6 & 7.4 \\
Account & 5 & 6.2 \\
Administration & 3 & 3.7 \\
Medical Social Worker & & \\
\hline Total & $\mathbf{8 1}$ & $\mathbf{1 0 0}$ \\
\hline
\end{tabular}


Table 4 shows that the core staff of the hospital, supposedly including the Nurses, Doctors, Dentists, Pharmacists, Physiotherapists and Laboratory workers, as seen in the table, constituted $76.6 \%$ of the respondents, an indication that all the core hospital staff needed for the purpose of this research are well represented.

Table 5: Distribution of the Respondents by Job Function

\begin{tabular}{|l|l|l|}
\hline Job Function & Number of Respondents & Percentage \\
\hline Managerial & 21 & 25.9 \\
Non-Managerial & 60 & 74.1 \\
\hline Total & $\mathbf{8 1}$ & $\mathbf{1 0 0}$ \\
\hline
\end{tabular}

Table 5 shows that the non-managerial staff among the respondents as revealed in the Table above constituted $74.1 \%$ of the respondents while $25.9 \%$ were managerial staff which include Head of Departments, Head of subunits and members of Hospital Management Committee, a confirmation of a good representation of all cadres of staff in the sample.

Table 6: "New Ways of Working" on staff satisfaction

\begin{tabular}{|c|c|c|c|c|c|c|c|c|c|}
\hline & Respo & ises* & & & & & & & \\
\hline STATEMENT & $\begin{array}{l}\text { SA } \\
\text { (\%) } \\
1\end{array}$ & $\begin{array}{l}\text { A } \\
(\%) \\
2\end{array}$ & $\begin{array}{l}\text { SMA } \\
(\%) \\
3\end{array}$ & $\begin{array}{l}\mathbf{N} \\
(\%) \\
4\end{array}$ & $\begin{array}{l}\text { SMD } \\
(\%) \\
5\end{array}$ & $\begin{array}{l}\mathbf{D} \\
(\%) \\
6\end{array}$ & $\begin{array}{l}\text { SD } \\
(\%) \\
7\end{array}$ & Mean & ${\text { St } \mathbf{D}^{+}}^{+}$ \\
\hline $\begin{array}{l}\text { I will be satisfied on my } \\
\text { job if I am given the } \\
\text { free hand to make } \\
\text { impactful decisions on } \\
\text { my work schedule. }\end{array}$ & $\begin{array}{l}31 \\
(25.9)\end{array}$ & $\begin{array}{l}39 \\
(48.2)\end{array}$ & $\begin{array}{l}\mathbf{1 3} \\
(16.1)\end{array}$ & $\begin{array}{l}\mathbf{4} \\
(4.9)\end{array}$ & $\begin{array}{l}\mathbf{1} \\
(1.2)\end{array}$ & $\begin{array}{l}\mathbf{2} \\
(2.5)\end{array}$ & $\begin{array}{l}\mathbf{1} \\
(1.2)\end{array}$ & 2.20 & 1.18 \\
\hline $\begin{array}{l}\text { I will be satisfied if I } \\
\text { am encouraged to } \\
\text { attend to my patients } \\
\text { using IT media in } \\
\text { addition to physical } \\
\text { attention. }\end{array}$ & $\begin{array}{l}\mathbf{5} \\
(6.2)\end{array}$ & $\begin{array}{l}25 \\
(30.9)\end{array}$ & $\begin{array}{l}\mathbf{1 3} \\
(16.1)\end{array}$ & $\begin{array}{l}7 \\
(8.6)\end{array}$ & $\begin{array}{l}\mathbf{5} \\
(6.2)\end{array}$ & $\begin{array}{l}\mathbf{1 8} \\
(22.2)\end{array}$ & $\begin{array}{l}\mathbf{8} \\
(9.9)\end{array}$ & 3.84 & 1.95 \\
\hline $\begin{array}{l}\text { I will be satisfied if I } \\
\text { am given more } \\
\text { independence in doing } \\
\text { my work. }\end{array}$ & $\begin{array}{l}\mathbf{1 4} \\
(17.3)\end{array}$ & $\begin{array}{l}39 \\
(48.2)\end{array}$ & $\begin{array}{l}\mathbf{2 0} \\
(24.7)\end{array}$ & $\begin{array}{l}\mathbf{3} \\
(1.2)\end{array}$ & $\begin{array}{l}\mathbf{2} \\
(2.5)\end{array}$ & $\begin{array}{l}\mathbf{1} \\
(1.2)\end{array}$ & $\begin{array}{l}\mathbf{0} \\
(0)\end{array}$ & 2.38 & 1.16 \\
\hline $\begin{array}{l}\text { I will be satisfied if I } \\
\text { am allowed to do some } \\
\text { of my official duties at } \\
\text { home. }\end{array}$ & \begin{tabular}{|l}
3 \\
$(3.7)$
\end{tabular} & $\begin{array}{l}\mathbf{9} \\
(11.1)\end{array}$ & $\begin{array}{l}\mathbf{1 2} \\
(14.8)\end{array}$ & $\begin{array}{l}\mathbf{1 0} \\
(12.4)\end{array}$ & $\begin{array}{l}6 \\
(7.4)\end{array}$ & $\begin{array}{l}\mathbf{3 0} \\
(37.0)\end{array}$ & $\begin{array}{l}\mathbf{1 1} \\
(13.6)\end{array}$ & 2.28 & 1.27 \\
\hline $\begin{array}{l}\text { I will be satisfied if I } \\
\text { am given the freedom } \\
\text { to determine the time of } \\
\text { starting and closing } \\
\text { each day work rather } \\
\text { than sticking to the } 8 \mathrm{am} \\
\text { to } 4 \mathrm{pm} \text { routine }\end{array}$ & \begin{tabular}{|l}
6 \\
$(7.4)$
\end{tabular} & $\begin{array}{l}\mathbf{8} \\
(9.9)\end{array}$ & $\begin{array}{l}\mathbf{8} \\
(9.9)\end{array}$ & $\begin{array}{l}\mathbf{8} \\
(9.9)\end{array}$ & $\begin{array}{l}\mathbf{5} \\
(6.2)\end{array}$ & $\begin{array}{l}31 \\
(38.3)\end{array}$ & $\begin{array}{l}\mathbf{1 5} \\
(18.5)\end{array}$ & 4.74 & 1.78 \\
\hline $\begin{array}{l}\text { I will be satisfied if I } \\
\text { am allowed to do my } \\
\text { private business }\end{array}$ & \begin{tabular}{|l}
3 \\
$(3.7)$
\end{tabular} & $\begin{array}{l}8 \\
(9.9)\end{array}$ & $\begin{array}{l}\mathbf{1 2} \\
(14.8)\end{array}$ & $\begin{array}{l}\mathbf{6} \\
(7.4)\end{array}$ & $\begin{array}{l}\mathbf{9} \\
(11.1)\end{array}$ & $\begin{array}{l}\mathbf{2 4} \\
(29.6)\end{array}$ & $\begin{array}{l}\mathbf{1 9} \\
(23.5)\end{array}$ & 4.86 & 1.92 \\
\hline
\end{tabular}


South American Journal of Public Health

Volume 4, Issue 2, 2016

\begin{tabular}{|c|c|c|c|c|c|c|c|c|c|}
\hline $\begin{array}{l}\text { alongside my work as a } \\
\text { hospital staff. }\end{array}$ & & & & & & & & & \\
\hline $\begin{array}{l}\text { I will be satisfied on my } \\
\text { job if the hospital } \\
\text { provides a means of } \\
\text { accessing relevant } \\
\text { information about my } \\
\text { work within the } \\
\text { hospital }\end{array}$ & $\begin{array}{l}\mathbf{4 1} \\
(50.6)\end{array}$ & $\begin{array}{l}33 \\
(40.7)\end{array}$ & $\begin{array}{l}\mathbf{5} \\
(6.2)\end{array}$ & $\begin{array}{l}\mathbf{0} \\
(0)\end{array}$ & $\begin{array}{l}\mathbf{0} \\
(0)\end{array}$ & $\begin{array}{l}\mathbf{1} \\
(1.2)\end{array}$ & $\begin{array}{l}\mathbf{1} \\
(1.2)\end{array}$ & 4.95 & 1.85 \\
\hline \multicolumn{8}{|l|}{ Average } & 3.52 & 1.54 \\
\hline
\end{tabular}

$*$ SA= Strongly Agree, $A=$ Agree. SMA= Somewhat Agree, $\mathbf{N}=$ Neutral, $\mathrm{SMD}=$ Somewhat Disagree, $\mathrm{D}=$ Disagree, $\mathrm{SD}=$ Strongly Disagree

Table 6 shows that the statement the respondents they will derive most satisfaction on their job if they are given the free hand to make impactful decisions on their work schedule, with a mean of 2.20 and a standard deviation of 1.18 , which is not too large indicating that the study instrument is a good measure of the variable.

Also the mean of Table 6 is 3.52 which showed that on the average the respondents marginally agreed that they will have more job satisfaction if 'New Ways of Working' is introduced into their hospital.

\section{Discussion}

There is a preponderance of female among the respondents $(69.1 \%)$, this is majorly because respondents in the nursing profession are all females and constituted a major part of the respondents $(35.8 \%)$, but both sexes are well represented. Majority of the respondents $(80.4 \%)$ are between 26 and 50 years age range, the active working age group, which means they are abreast of the 'going-ons' in the organization, and since they are the pleasure seeking group, it then means they will be able to discern easily what gives them satisfaction and overall, the data shows that all working age groups are represented.. A significant chunk of the respondents $(65.5 \%)$ have more than a bachelor degree, with $20.8 \%$ of these group of respondents even having a post-graduate degree, which means their responses are not hampered by lack of education and understanding of the hospital system.

The core staff of the hospital, supposedly including the Nurses, Doctors, Dentists, Pharmacists, Physiotherapists and Laboratory workers, as seen in the table, constituted $76.6 \%$ of the respondents, an indication that all the core hospital staff needed for the purpose of this research are well represented. The non-managerial staff among the respondents constituted $74.1 \%$ of the respondents while $25.9 \%$ were managerial staff which include Head of Departments, Head of subunits and members of Hospital Management Committee, a confirmation of a good representation of all cadres of staff in the sample.

This study reveals that on the average, the respondents perceive that they will derive more satisfaction by imbibing a new way of working different from what they are actually used to. This finding is in consonance with the assertion by Stam (2011) that NWW satisfies employees' need, and lead to greater motivating effect on staff (Baane et al. 2010) but this was disputed by Stoffers et al., (2015) that this was not usually the case in many practical studies they undertook. Though, undisputedly, Bijl (2007, 2009), Blok et al., (2012) and Stoffers et al. (2015) concurred that rather than NWW satisfying employees it is only some components of NWW like the work environment and technology pillars that improve staff satisfaction. However, Beech (2002) stated that improving leadership within the organization should enable a more effective implementation and ownership of changes and improve job satisfaction and career advancement, and so it has to be discerned and practicalised in paripassu.

However, out of all the components of NWW that the respondents in this study responded to, they tend to believe they would have more satisfaction when they are allowed the freedom 
to make impactful decisions on their work schedules. This finding is line with the assertion of Berlowitz et al, 2003, who affirmed that organizations that focus on empowering nurses can help in them taking more active roles in daily care decisions, which is believed to enhance employee satisfaction. Also, Relf (1995) established that when employees are more active in decision making, they feel more engaged which leads to higher satisfaction and lower turnover rates.

\section{Conclusion}

This study, thus, make the following conclusion:

On the average the respondents believe they will derive more satisfaction on the introduction of new ways of working in General Hospitals in Nigeria. They however believed they will derive the least satisfaction when the hospital make provision for them with means of accessing information relevant to their work within the hospital $(4.95 \pm 1.85)$. However, they were able to establish that when they are given a chance to make impactful decisions on their work schedules they will derive the highest level of satisfaction $(2.20 \pm 1.18)$.

\section{Recommendations}

New Ways of Working should be sold more solidly to staff, since they have shown that they will surely derive some satisfaction with its introduction and implementation, and also its benefits should be inculcated into the psyche of policy makers, since expectedly, it will also be satisfying to patients as well because of the flexibility it will afford them to receive health care from these hospitals.

\section{Suggestions for further studies}

More respondents from more General Hospitals in Nigeria should be involved in future studies so as to further establish the satisfaction that this concept of 'New Ways of Working' will bring to staff of these hospitals and in extension to their patients.

\section{References}

[1.] Al-Tawfiq JA, Memish ZA: What are our pharmacotherapeutic options for MERS-CoV?. Expert Rev Clin Pharmacol. 2014, 7: 235-238. 10.1586/17512433.2014.890515.

[2.] Baane, R. H., Houtkamp, p., Knotter, M., (2010). Het nieuwewerkenontrafeld [New ways of working figured out]. Assen: Koninklijke Van Gorcum.

[3.] Baruch, Y. (2001). The status of research on teleworking and an agenda for future. International Journal of Management Reviews, 3(2), 113-129.

[4.] Bass, B., Avolio, B., \& Atwater, L. (1996). The transformational and transactional leadership of men and women. Applied Psychology, 45(1), 5-34.

[5.] Bass, B., Avolio, B., Jung, D. I., \& Berson, Y. (2003). Predicting unit performance by assessing transformational and transactional leadership. Journal of Applied Psychology, 88(2), 207.

[6.] Berlowitz, D. R., Young, G. J., Hickey, E. C., Saliba, D. Mittman, B. S., Czarnowski, E., Simon, B., Anderson, J. J., Ash, A. S., Rubenstein, L. V., and Moskowitz, M. A. (2003), Quality improvement implementation in the nursing home, Health Services Research 38, Part 1, 65-80.

[7.] Bijl, D., \& Gray, M. (2011). Journey Towards the New Way of Working: Creating Sustainable Performance and Joy at Work. Par CC.

[8.] Bijl, D., (2007). Het nieuwewerken: Op wegnaareenproductievekenniseconomie [New Ways of working: heading for a productive knowledge economy]. Den Haag: Sdu Publishers bv.

[9.] Bijl, D., (2009). Aan de slag met het nieuwewerken [Let's get to the new ways of working]. Zeewolde: Par CC.

[10.] Blok, M., Groenesteijn, L., Berg, C. Van Den, \& Vink, P. (2011). New Ways of Working: A Proposed Framework and Literature Review. Ergonomics and Health Aspects of Work with Computers, $3-12$. 
South American Journal of Public Health

Volume 4, Issue 2, 2016

[11.] Blok, M. M., Groenesteijn, L., Schelvis, R., \& Vink, P. (2012). New ways of working: does flexibility in time and location of work change work behavior and affect business outcomes? Work: A Journal of Prevention, Assessment and Rehabilitation, 41, 5075-5080.

[12.] Bryman, A., \& Bell, E. (2011). Business Research Methods (3rd edition). New York: Oxford University Press Inc.

[13.] Cameron, K. S., \& Quinn, R. E., (2008). Onderzoekenenveranderen van organisatiecultuur [Researching and changing organizational culture]. Den Haag: Sdu Publishers bv.

[14.] Cronbach L.J., (1951) Coefficient alpha and the internal structure of tests. Psychometrika 16:297-334.

[15.] De Leede, J., \& Kraijenbrink, J. (2014). The Mediating Role of Trust and Social Cohesion in the Effects of New Ways of Working: A Dutch Case Study. Human Resource Management, Social Innovation and Technology (Advanced Series in Management, Volume 14). England. Emerald Group Publishing Limited, 14, 3-20.

[16.] Doherty, S., Andrey, J., \& Johnson, L. (2000). The economic and social impacts of telework. In Telework: The New Workplace of the 21st Century Symposium, New Orleans.

[17.] Dooley, D. (2009). Social research methods (4th edition). Harlow: Pearson Education Limited.

[18.] Egmond van, H., (2010). Het nieuwewerken: Van visienaarpraktijk [New ways of working: From vision to practice]. Alphen aan den Rijn: Kluwer.

[19.] Gates, B. (2005). Digital Workstyle: The New World of Work A Microsoft White Paper.

[20.] Gautret P, Benkouiten S, Salaheddine I, Belhouchat K, Drali T, \& Parola P., (2013). Hajj pilgrims knowledge about Middle East respiratory syndrome coronavirus, August to September 2013. Euro Surveill. 2013, 18: 20604.

[21.] Haterd van de, B., (2010). Werkennieuwestijl [Working on a new style]. Amersfoort: A.W. Bruna Publishers B.V.

[22.] Keuning, D., (2007). Structuurdoorzien [Structure seen]. Groningen: Wolters Noordhoff.

[23.] Kok, A. de, Koops, J., and Helms, R. W. (2014), Assessing the new way of working: bricks, bytes and behaviour. Pacis 2014 Proceedings. Paper 7. http://aisel.aisnet.org/pacis2014/

[24.] Kuipers, H., Amelsvoort, P., \& Kramer, E.H., (2010). Het nieuweorganisatie: Alternatieven voor de bureaucratie [New ways of organizing: Alternatives for bureaucracy]. Leuven: Acco.

[25.] Memish ZA, Al-Tawfiq JA, Makhdoom HQ, Al-Rabeeah AA, Assiri A, Alhakeem RF, Alrabiah FA, Alhajjar S, Albarrak A, Flemban H, Balkhy H, Barry M, Alhassan S, Alsubaie S, \& Zumla A., (2014). Screening for Middle East respiratory syndrome coronavirus infection in hospital patients and their healthcare worker and family contacts: a prospective descriptive study. ClinMicrobiol Infect. 2014, 20: 469-474. 10.1111/1469-0691.12562.

[26.] Newman, K., Maylor, U., \& Chansarkar, B. (2001) "The nurse retention, quality of care and patient satisfaction chain", International Journal of Health Care Quality Assurance, Vol. 14 Iss: 2, pp.57 - 68. DOIhttp://dx.doi.org/10.1108/09526860110386500

[27.] Nunnally, J. (1978). Psychometric theory (Second edition). New York: McGraw-Hill.

[28.] Relf, M. (1995), Increasing job satisfaction and motivation while reducing nursing turnover through the implementation of shared governance, CriticalCare Nursing Quarterly 18, 3, 7-13.

[29.] Saunders, M., Lewis, P., Thornhill, A., Booij, M., and Verckens, J. P., (2011). Methodenen technieken van onderzoek [Methods and techniques of research]. Amsterdam: Pearson Education Benelux.

[30.] Slijkhuis, J. M. (2012). A Structured Approach to Need for Structure at Work. University Library Groningen.

[31.] Stam, P., (2011). Het nieuwewerkenmeegewogen [New ways of working weighed in]. Utrecht: Utrecht University.

[32.] Stoffers J., Kurstjens J., \& Schrijver I.(2015). Leadership and New Ways of Working: A Case Study in a Financial Service Organisation. International Journal of Business and Economics Research. Vol. 4, No. 3, 2015, pp. 157-162. doi: 10.11648/j.ijber.20150403.18

[33.] Volberda, H., Jansen, J., Tempelaar, M., \& Heij, K., (2011). Monitoren van sociale innovatie: Slimmer werken, dynamischmanagenen flexible organiseren: Monitoring social innovation: working smarter, dynamic management and organising flexible. Magazine for HRM, 1, 85-110. 
South American Journal of Public Health

Volume 4, Issue 2, 2016

[34.] Wensing, L., (2009). Technologie is enblijft de sleutel tot het nieuwewerken [Technology is and remains the key to New Ways of Working]. Retrieved from: http://hetnieuwewerkenblog.nl/technologie-sleutel-hetnieuwe- werken/

[35.] WHO MERS-CoV Research Group, (2013). State of knowledge and data gaps of Middle East Respiratory Syndrome coronavirus (MERS-CoV) in humans. PLoSCurr. 2013, 5 